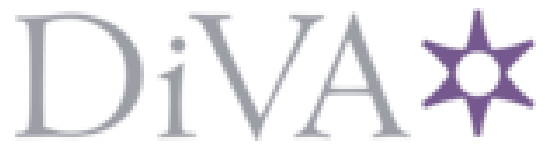

http://www.diva-portal.org

Preprint

This is the submitted version of a paper presented at 2012 IEEE International Conference on Condition Monitoring and Diagnosis, 23-27 September 2012, Bali, Indonesia.

Citation for the original published paper:

Ohlen, M., Werelius, P., Cheng, J., Skoldin, J. (2012)

Best Practices For Dielectric Frequency Response Measurements and Analysis in RealWorld Substation Environment

In: , E-13

N.B. When citing this work, cite the original published paper.

Permanent link to this version:

http://urn.kb.se/resolve?urn=urn:nbn:se:kth:diva-303018 


\section{Best Practices For Dielectric Frequency Response Measurements and Analysis in Real-world Substation Environment}

\author{
Matz Ohlen \\ Megger \\ Täby, Sweden \\ matz.ohlen@megger.com
}

\author{
Peter Werelius \\ Megger \\ Täby, Sweden \\ peter.werelius@megger.com
}

\author{
Jialu Cheng \\ Megger \\ Täby, Sweden \\ jialu.cheng@megger.com
}

\author{
Joacim Skoldin \\ Megger \\ Täby, Sweden \\ joacim.skoldin@megger.com
}

\begin{abstract}
Modern technology and developments in signal acquisition and analysis techniques have provided new tools for transformer and bushing diagnostics. Of particular interest are dielectric response measurements where insulation properties of oil-paper systems can be investigated. Dielectric Frequency Response, DFR (also known as Frequency Domain Spectroscopy, FDS), was introduced more than 20 years and has been thoroughly evaluated in a number of research projects and field tests with good results. DFR data in combination with mathematical modeling of the oil-paper insulation is proven as an excellent tool for moisture and oil conductivity assessment of power transformers.

Dielectric response measurements are usually performed at a much lower voltage level than traditional power frequency tandelta measurements. Due to this, the signal-to-noise ratio may sometimes be extremely low, especially at low frequencies and when measuring low capacitance objects e.g. bushings and instrument transformers. The interference suppression capability of the test set thus becomes an important parameter when considering different methods and instruments.

In this paper investigation of the electromagnetic interference in terms of $\mathrm{AC}$ hum currents, induced DC currents and low frequency interference in $\mathrm{AC}$ as well as HVDC substations are presented. Solutions to handle these different types and levels of interference are investigated and examples of measurements under those conditions are presented.

The paper also covers DFR response analysis using the XYmodel. Numerical analysis using COMSOL has been performed and compared with the simplified analytical XY-model to investigate how non-ideal conditions influence geometry parameters and results.
\end{abstract}

Keywords-Dielectric frequency response; DFR; frequency domain spectroscopy; FDS; power factor; dissipation factor; temperature correction; temperature dependence; power transformer; moisture; interference; insulation; modeling

\section{INTRODUCTION}

The widely accepted and most common insulation diagnostic test is carried out measuring capacitance and dissipation factor (tan-delta) at power frequency $(50 / 60 \mathrm{~Hz})$. The results are often recalculated to an estimated value at $20^{\circ} \mathrm{C}$ reference temperature using fixed temperature correction factors (TCF) and analysis is based on historical values (trending analysis) and comparing against factory values [1].

Dielectric frequency response measurements (DFR) are an extension of the traditional tests. Instead of measuring the dissipation factor at power frequency only, the DFR measurement is performed over a wide frequency range, typically from $1 \mathrm{mHz}$ to $1 \mathrm{kHz}$. The measured results are used for modeling the insulation and the analysis can provide accurate tan-delta at $20^{\circ} \mathrm{C}$ reference temperature, moisture in the solid insulation, measured oil conductivity (or dissipation factor at power frequency) and oil conductivity at $25^{\circ} \mathrm{C}$ reference temperature. All in one single test that takes typically $20-40$ minutes.

\section{Dielectric FreQuency Response Measurements AND ANALYSIS}

\section{A. Moisture and Oil Assessment}

The first field instrument for DFR measurements of transformers, bushings and cables was introduced in 1995 [2]. Since then numerous research groups have evaluated DFR technology used for field measurement. Several international projects/reports define dielectric response measurements together with insulation modeling as the preferred method for measuring moisture content of the cellulose insulation in power transformers [3-5].

DFR measurement combined with mathematical modeling of the dielectric response using the so called XY model can be used for estimating moisture in solid insulation, dielectric properties of the oil as well as temperature dependence of the insulation system in power transformers and other oil-paper insulation systems. The methodology has been described in numerous papers and the interested reader can get a lot of detailed information in the reference list.

The results are normally presented as capacitance and/or dissipation factor versus frequency. DFR results and analysis for three typical transformers are shown in Fig. 1. 


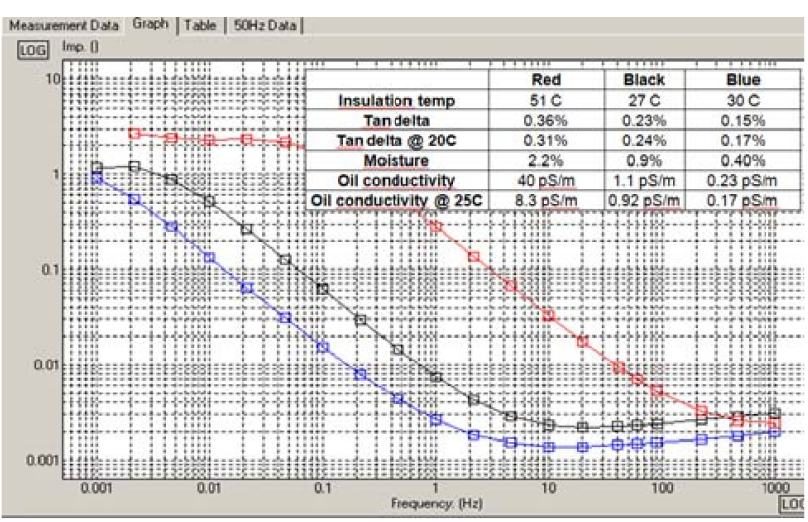

Figure 1. DFR measurement and analysis examples of three different transformers

\section{B. Temperature Dependence}

Samples of Kraft paper with various moisture contents were measured at different temperatures [6]. Results for dry paper, moisture content $<1 \%$ are shown in Fig. 2.

The dissipation factor at $50 \mathrm{~Hz}$ as a function of temperature for dry Kraft paper measured as a function of frequency at several temperatures is presented in Fig. 3.

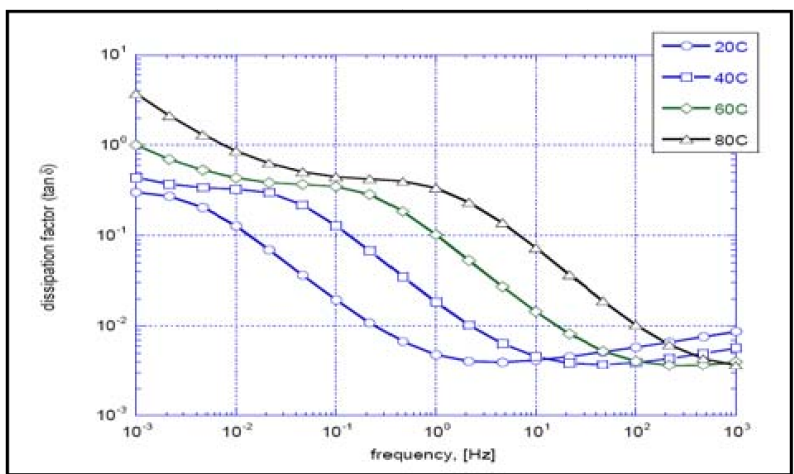

Figure 2. Dissipation factor as function of frequency for dry Kraft paper.

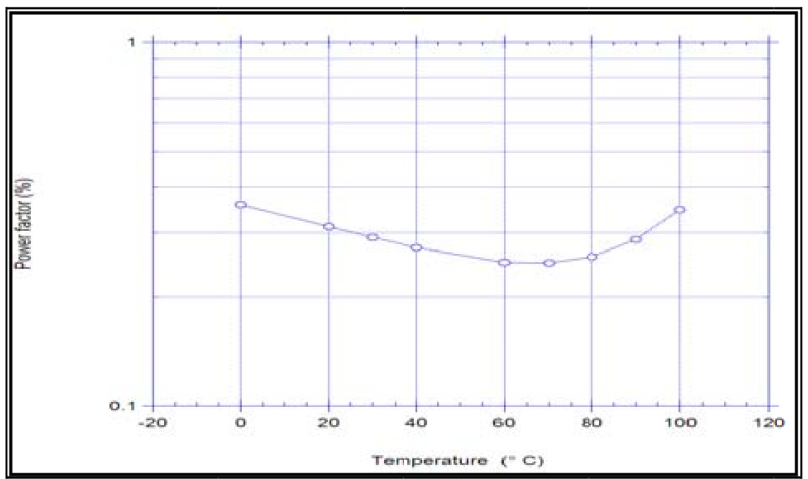

Figure 3. Dissipation factor $(50 \mathrm{~Hz})$ as function of temperature for dry Kraft paper.

The methodology on using DFR to analyze the temperature dependence of transformers and bushings has been presented in several publications $[7,8]$. Of fundamental importance is the relationship between insulation temperature and frequency response. A measurement at one frequency at one temperature corresponds to a measurement at another frequency at a different temperature. The dielectric response moves to higher frequency with temperature increase. This behavior is depicted in Fig. 4 for three different activation energies.

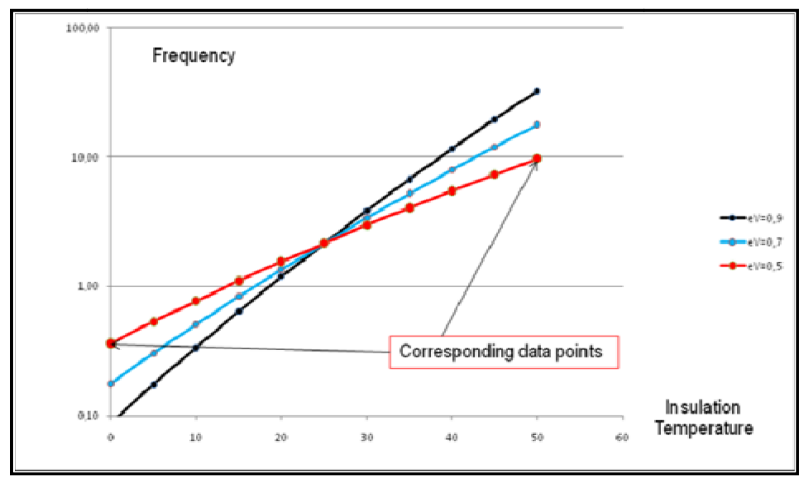

Figure 4. Relationship between power factor values at different frequencies taken at different temperatures.

The combined type insulation system of power transformers consisting of paper/pressboard and oil requires deeper investigation. In this complex insulation system, the temperature correction factors are a combination of temperature dependence of cellulose and temperature dependence of oil. Also, the amount of cellulose and oil need to be taken into account.

An example for a power transformer is shown in Fig. 5 and 6. The unit is a 20 MVA core type distribution transformer with $1.9 \%$ moisture, measured at $16^{\circ} \mathrm{C}$ insulation temperature.

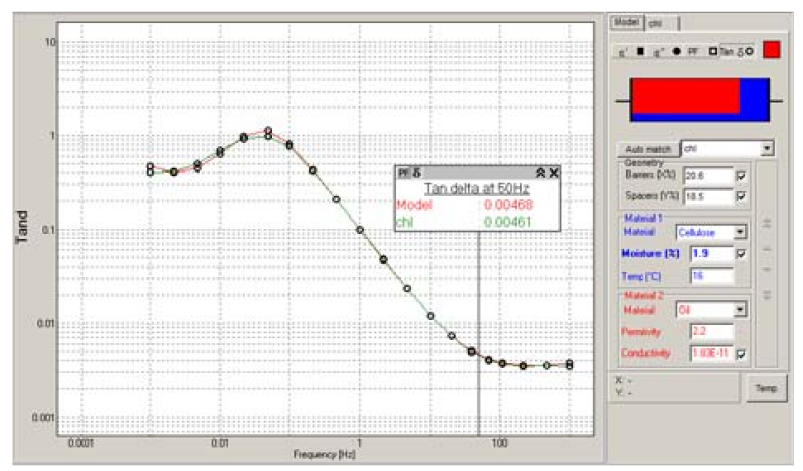

Figure 5. $\operatorname{MODS}\left({ }^{(}\right)$moisture and oil analysis for a 20 MVA transformer 


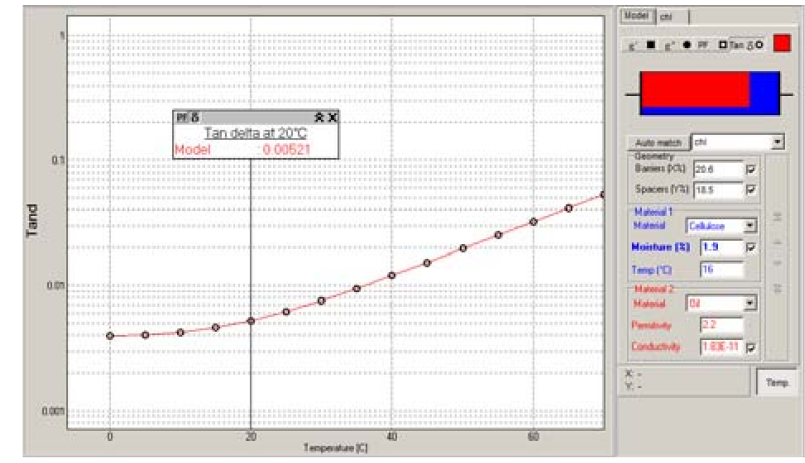

Figure 6. Dissipation factor $(50 \mathrm{~Hz})$ as function of temperature for a $20 \mathrm{MVA}$ distribution transformer

An example of bushing diagnostics using temperature dependence analysis is shown in Figures 7 and 8 . Three $26 \mathrm{kV}$ OIP bushings were measured at about $10^{\circ} \mathrm{C}$ insulation temperature. The tan delta values at power frequency are all within the traditional "OK" limit of "less than two times nameplate" (according to the manufacturers specification there is no temperature correction from 10 to $20^{\circ} \mathrm{C}$ ). However if you look at the temperature dependence it is clear that the X3 bushings have a strong temperature dependence, very different from the manufacturers TCF, and should be replaced.

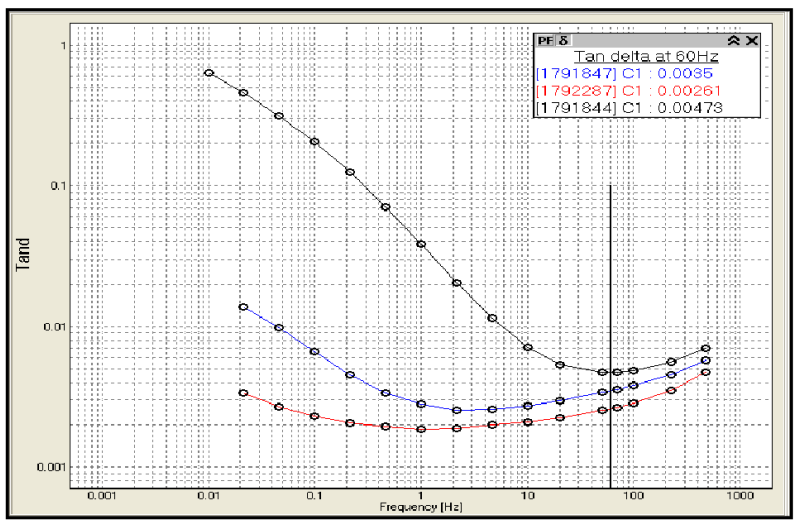

Figure 7. DFR measurement (C1) on $26 \mathrm{kV} \mathrm{GE}$ type $\mathrm{T}$ bushings

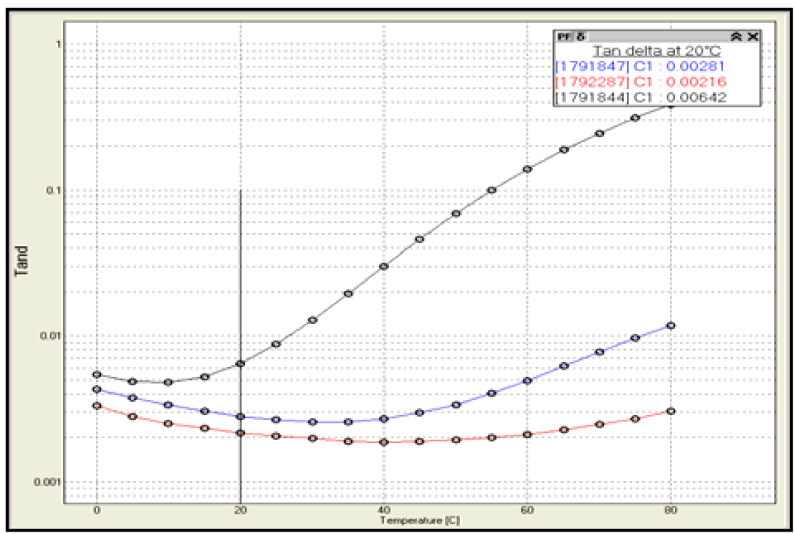

Figure 8 . Figure 24. Tan delta temperature dependence, $26 \mathrm{kV}$ GE type T bushings

\section{INTERFERENCE INFLUENCE IN DFR MEASUREMENTS}

There are different kinds of interference present in a substation. AC interference a power frequency and its harmonics, DC offset current and low frequency interference (VLF) caused by slowly varying DC current. Example of DC and VLF interference is corona discharges [9]. Statistical data from 100 typical measurements are presented in Fig. 9.

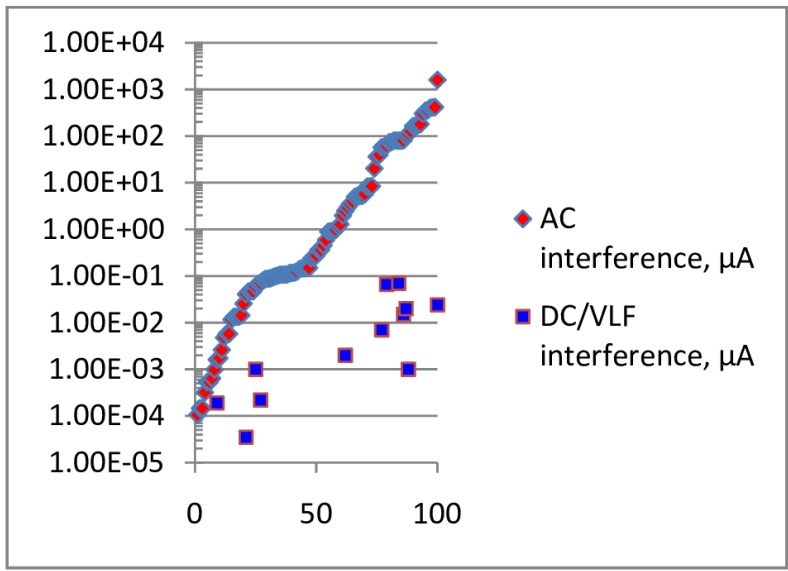

Figure 9. $\mathrm{AC}$ and $\mathrm{DC}$ interference levels in substation environment

DFR measurements can be performed with DC or AC technique at low or high voltage and the different techniques do not have the same capability to handle high interference levels. A general summary of noise suppression performance is presented in Table I.

TABLE I. INTERFERENCE SENSITIVITY FOR DifFERENT DFR TECHNOLOGIES

\begin{tabular}{|c|c|c|c|}
\hline \multirow{2}{*}{$\begin{array}{c}\text { Interference } \\
\text { signals }\end{array}$} & \multicolumn{3}{|c|}{ DFR Measurement Technologies } \\
\cline { 2 - 4 } & Low Voltage DC & Low Voltage AC & High Voltage AC \\
\hline $\mathrm{AC}(50 / 60 \mathrm{~Hz})$ & Sensitive & Not sensitive & Not sensitive \\
\hline $\mathrm{DC} / \mathrm{VLF}$ & Very sensitive & Sensitive & Not sensitive \\
\hline
\end{tabular}

Especially the low frequency ("VLF") interference and "DC" interference, may interfere with low frequency Dielectric Response (DR) measurements and is therefore of special importance. Using time domain measurements with applied DC voltage (Polarization Current Measurements), it is not possible to separate a leakage (high loss insulation) current from an interference DC current and the resulting DFR response will have significant errors at low frequencies. AC methods are principally not sensitive DC offset as long as the amplitude is within the capability of the current measurement channel and $\mathrm{AC}$ interference can be rejected by using advanced digital filtering and in situations with very high interference, adding an amplifier that increases the test voltage to $2 \mathrm{kV}$ (peak). 
An example of quite extreme conditions that sometimes occur even in a "normal" substation is presented in Fig. 10. Test data:

- $400 \mathrm{kV}$ single-phase three-winding transformer

- $\mathrm{AC}$ interference: $1.6 \mathrm{~mA}$

- DC interference: $24 \mu \mathrm{A}$

- Capacitance: $3160 \mathrm{pF}$

- Tan delta: $0.30 \%$

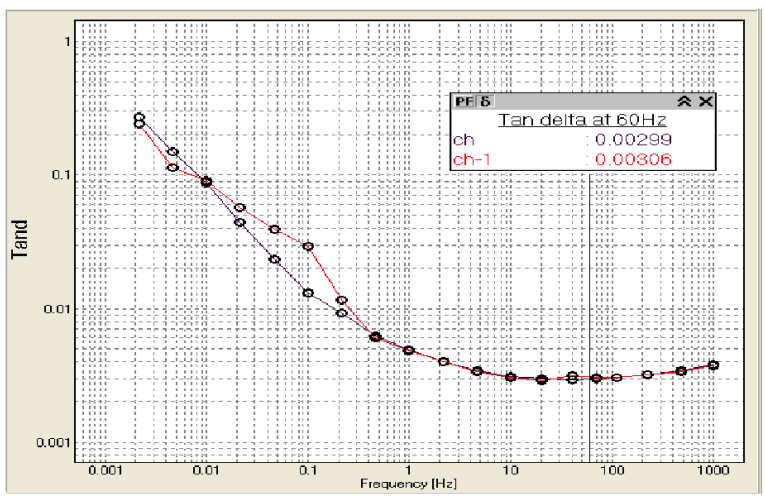

Figure 10. DFR results, GST measurements. Red; $140 \mathrm{~V}$ test voltage, Blue; $1400 \mathrm{~V}$ test voltage

Power frequency tan delta values are not affected by the very high interference even when using low voltage AC technique $(140 \mathrm{~V})$. Low frequency data are strongly affected by the interference but when applying higher test voltage $(1.4$ $\mathrm{kV}$ ) the influence of AC and VLF interference disappears.

\section{DFR MODELING USING FEM ANALYSIS}

DFR measurements on transformers and bushings in combination with insulation modeling are a good tool for investigating and understanding the properties of an insulating material. The model used for describing the insulation system inside a transformer is usually called and described as an XYmodel. A simplified insulation structure is represented by the relative amount of spacers (sticks) and barriers in the cooling duct as shown in Fig. 1. Parameter X, is defined as the ratio of the sum of all barriers in the duct, lumped together, and divided by the duct width. The spacer coverage $\mathrm{Y}$ is defined as the total width of all the spacers divided by the total length of the periphery of the duct.

The total dielectric response of the XY model can be calculated by four capacitors in series and parallel with each other. Dividing the geometry capacitor, the total permittivity could be obtained. The widely applied method is that the capacitors are in series in $\mathrm{X}$ direction and in parallel in $\mathrm{Y}$ direction.

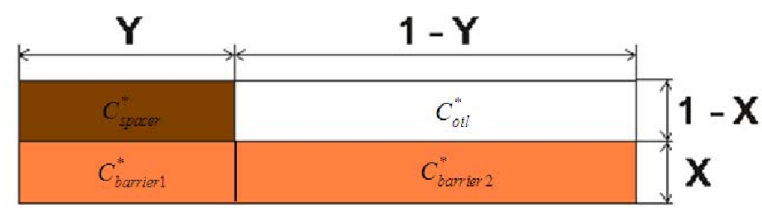

Figure 11. Capacitor model of the XY model

$$
\varepsilon(\omega, T)_{1}=\frac{Y}{\frac{1-X}{\varepsilon_{\text {spacer }}}+\frac{X}{\varepsilon_{\text {barrier } 1}}}+\frac{1-Y}{\frac{1-X}{\varepsilon_{\text {oil }}}+\frac{X}{\varepsilon_{\text {barrier } 2}}}
$$

\section{A. Geometry Influence}

A frequent question when modeling the transformer insulation is what insulation geometry should be used. Should the "true" geometry for the design be used or can I rely on the modeling SW to find my geometry? Let's look at a typical DFR measurement and analysis for a service aged power transformer and see what differences we get when using "true" or "free" geometry.

As seen in the figures, the match between measured and modeled response is somewhat better when using auto geometry, i.e. the geometry for the modeled transformer is allowed to vary within a certain range. Does this mean more accurate analysis?

Table II presents a summary of the analysis. Using auto geometry gives somewhat lower moisture and somewhat higher modeled oil conductivity. What values describe the actual transformer the best?

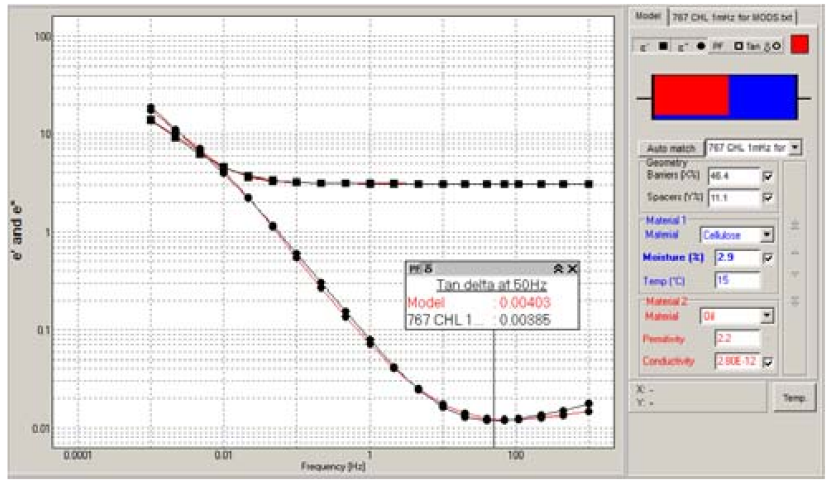

Figure 12. DFR modeling using auto geometry matching 


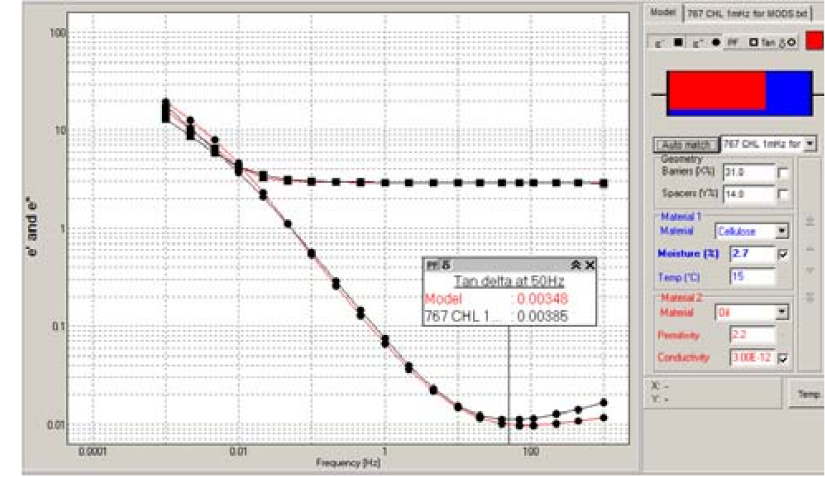

Figure 13. DFR modeling using "true/fixed" geometry

TABLE II. RESULTS FROM DFR ANALYSIS USING FIXED AND AUTO GEOMETRY

\begin{tabular}{|c|c|c|c|}
\hline Parameter & $\begin{array}{c}\text { Fixed } \\
\mathbf{X} \& \mathbf{Y}\end{array}$ & $\begin{array}{c}\text { Auto } \\
\mathbf{X} \& \mathbf{Y}\end{array}$ & $\begin{array}{c}\text { Change of results, } \\
\text { Auto to Fixed }\end{array}$ \\
\hline X-geometry (\%) & 31 & 46 & $+48 \%$ \\
\hline Y-geometry (\%) & 14 & 11 & $-21 \%$ \\
\hline Tan-delta (\%) & 0.36 & 0.36 & $+/-0 \%$ \\
\hline Tan-delta @, 20C (\%) & 0.37 & 0.37 & $+/-0 \%$ \\
\hline Moisture (\%) & 2.7 & 2.9 & $+16 \%$ \\
\hline Oil conductivity (pS/m) & 3.0 & 2.8 & $-7 \%$ \\
\hline
\end{tabular}

\section{B. Insulation modelling using Finite Element Methods}

The main problem of the simplified capacitor model is that it neglects the electric field distortion due to various edge effects. To get an idea of how this influence the accuracy of the model, three geometry effects have been investigated with FEM analysis using COMSOL.

\section{1) "Corner effect"}

Fig. 16 shows a simulation of voltage distribution in the oil-paper system at $0.01 \mathrm{~Hz}$ in COMSOL. The distorted equal potential lines show that the electric field is non-uniform at physical corners in the insulation structure.

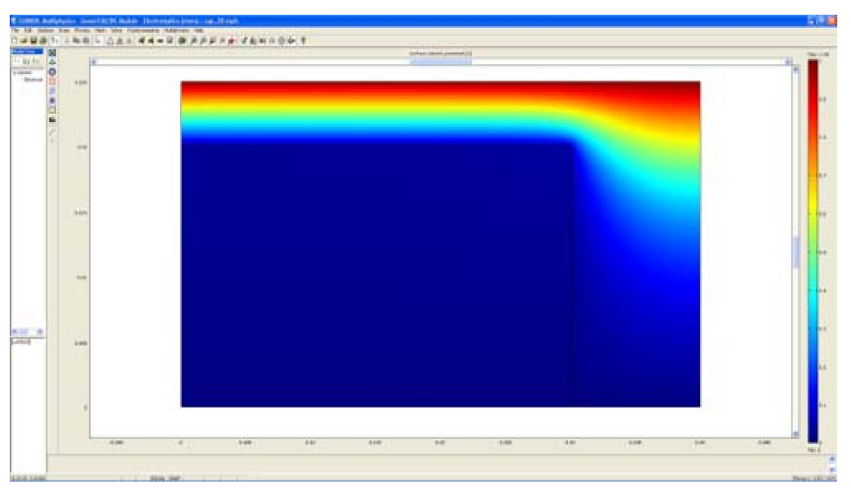

Figure 14. Simulation of the oil-paper system at $0.01 \mathrm{~Hz}$

2) Non-aligned sticks

Fig. 15 shows a simulation of non aligned sticks/spacers in the cooling duct between LV and HV windings

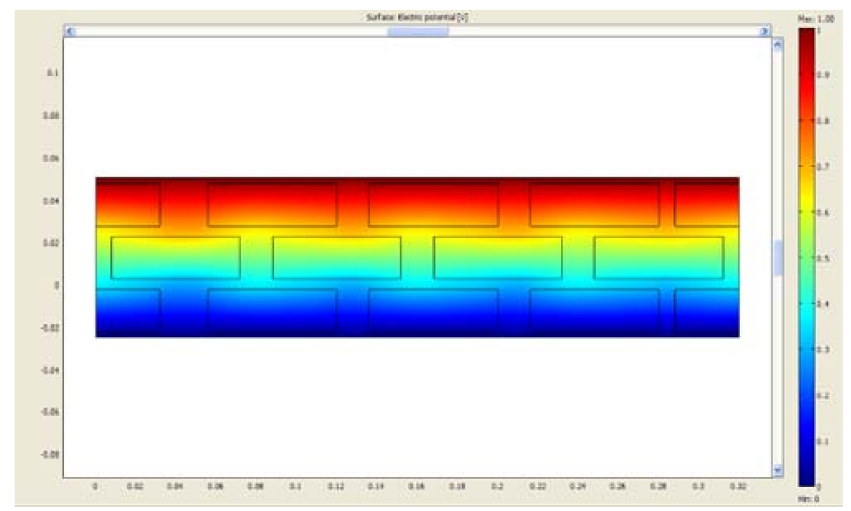

Figure 15. Simulation of non-aligned stick in the cooling duct

3) Non-uniform capacitor electrode

In the X-Y model, the capacitance is formed by the two windings as capacitor plates and the oil-cellulose structure as the dielectric medium between the plates. The plates are assumed to be flat and continuous but in a real winding there are spaces between winding turns that forms a non-uniform electrode. Fig. 16 shows a simulation of a transformer winding with $25 \%$ spacing between the individual turns.

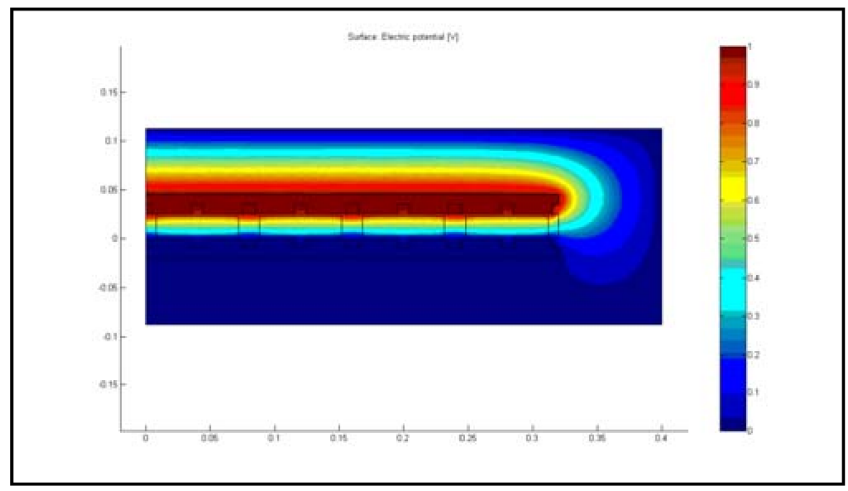

Figure 16. Simulation of non-uniform capacitor surface

\section{Comparing FEM and $X-Y$ model}

To see how the discontinuity effects may influence moisture and oil assessment when using traditional XY-modeling, the results from the FEM simulations above have been used as measurement data for a typical core form power transformer design $(X / Y=20 / 20)$ with 1 and 3\% moisture. Analysis has been performed with fixed $20 / 20$ geometry settings and automatic geometry matching. Results are presented in Table III. 
TABLE III. RESULTS FROM DFR ANALYSIS USING FIXED AND AUTO GEOMETRY

\begin{tabular}{|c|c|c|c|c|}
\hline Discontinuity - "corner" & $X(\%)$ & $Y(\%)$ & $\begin{array}{c}\text { Oil } \\
\text { conductivity } \\
(\mathrm{pS} / \mathrm{m})\end{array}$ & $\begin{array}{c}\text { Moisture } \\
\text { content } \\
(\%) \\
\end{array}$ \\
\hline FEM Model & 20 & 20 & 1 & $1.0 / 3.0$ \\
\hline Fixed Geometry & 20 & 20 & $1.0 / 1.0$ & $1.0 / 3.0$ \\
\hline $\begin{array}{l}\text { Fixed Moisture \& oil } \\
\text { cond. }\end{array}$ & $19.2 / 17.5$ & $20.6 / 21.6$ & $1.0 / 1.0$ & $1.0 / 3.0$ \\
\hline \multicolumn{5}{|l|}{$\begin{array}{c}\text { Discontinuity - } \\
\text { "stickers" }\end{array}$} \\
\hline FEM Model & 20 & 20 & 1 & $1.0 / 3.0$ \\
\hline Fixed Geometry & $20.0 / 20.0$ & $20.0 / 20.0$ & $1.1 / 1.3$ & $0.8 / 2.7$ \\
\hline $\begin{array}{l}\text { Fixed Moisture \& oil } \\
\text { cond. }\end{array}$ & $21.6 / 23.3$ & $15.9 / 15.0$ & 1 & $1.0 / 3.0$ \\
\hline \multicolumn{5}{|l|}{ Discontinuity - "plate" } \\
\hline FEM Model & 20 & 20 & 1 & $1.0 / 3.0$ \\
\hline Fixed Geometry & 20 & 20 & 1.1/1.3 & $0.8 / 2.7$ \\
\hline $\begin{array}{l}\text { Fixed Moisture \& oil } \\
\text { cond. }\end{array}$ & $18.4 / 18.6$ & $15.2 / 15.0$ & 1 & $1.0 / 3.0$ \\
\hline
\end{tabular}

Using "fixed/true" insulation geometry, the analysis may give $10-30 \%$ error for the moisture and oil assessment. For "true" moisture and oil results, a geometry difference of about $5 \%$ for a single discontinuity effect must be allowed. These preliminary findings support that allowing "free/auto" geometry optimization in the example in Figures 12-13 most probably result in more accurate moisture and oil assessment.

\section{SUMMARY AND CONCLUSIONS}

Dielectric Frequency Response (DFR/FDS) measurement is a technique/methodology for general insulation testing and diagnostics. In comparison with $50 / 60 \mathrm{~Hz}$ dissipation factor measurements, DFR measurements in combination with insulation modeling provide the following advantages:

- Capability of estimating the moisture content of solid insulation and oil conductivity in oil-immersed power transformers

- Capability of performing individual temperature correction of measured $50 / 60 \mathrm{~Hz}$ dissipation factor at various temperatures to values at reference temperature, $20^{\circ} \mathrm{C}$.

- Capability of estimating temperature dependence in an object and from measured dissipation factor at a certain temperature calculate the dissipation factor at a different temperature

- Capability of generally investigating causes for increased dissipation factor in power components

Substation interference can easily give measurement errors in DFR measurements if the test system has low noise suppression capability. AC frequency domain measurements of dielectric response has taken two steps further decreasing the susceptibility to high interference in AC as well as HVDC substations by implementing advanced digital filter algorithms and in severe cases also adding a $2 \mathrm{kV}$ amplifier to increase test voltage.

Insulation geometry is an important parameter when modeling the insulation system in a transformer. Comparing FEM analysis with the analytical X-Y capacitance model indicates that allowing geometry deviation from the "true" values may increase the accuracy for moisture and oil assessment.

\section{REFERENCES}

[1] IEEE Guide for Diagnostic Field Testing of Electric Power Apparatus; Part 1: Oil Filled Power Transformers, Regulators, and Reactors", IEEE 62-1995

[2] P. Werelius et al, "Diagnosis of Medium Voltage XLPE Cables by High Voltage Dielectric Spectroscopy”, paper presented at ICSD 1998

[3] S.M. Gubanski et al, "Dielectric Response Methods for Diagnostics of Power Transformers", Electra, No. 202, June 2002, pp 23-34, also in CIGRE Technical Brochure, No. 254, Paris 2004

[4] S.M. Gubanski et al, "Reliable Diagnostics of HV Transformer Insulation for Safety Assurance of Power Transmission System. REDIATOOL - a European Research Project", paper D1-207 CIGRE 2006

[5] S.M. Gubanski et al, CIGRE report 414, Dielectric Response Diagnoses For Transformer Windings, 2010

[6] R. Neimanis, T. Saha, and R. Eriksson, "Determination of moisture content in mass impregnated cable insulation using low frequency dielectricspectroscopy," IEEE Power Engineering Society Summer Mecting, 2000, vol. 1, pp. 463-468 vol. 1, 2000.

[7] P. Werelius, M. Ohlen, "Dielectric Frequency Response Measurements on Power Transformers", EuroTechCon 2008, Liverpool, UK

[8] M. Ohlen, P. Werelius, "Dielectric Frequency Response and Temperature Dependence of Power Factor", IEEE-ISEI 2010, San Diego, USA

[9] J. Skoldin, P. Werelius and M. Ohlen, "Dielectric Frequency Response Measurement Technology for Measurements in High Interference AC and HVDC Substations", TechCon Asia-Pacific, 2011, Sydncy, Australia 